\title{
Experience of a Medical School in the Philippines on the Sudden Shift to Online Learning amidst COVID-19
}

\author{
Raymundo S. Baquiran, MD, MPH and Kirk C. Plata, MD, MBA \\ Ateneo de Manila University School of Medicine and Public Health
}

\begin{abstract}
Introduction. The COVID-19 pandemic forced educational institutions to adapt to a full online learning environment. Medical schools in particular were disrupted by this shift since the majority of the learning objectives, skills, and necessary competencies are learned through classroom and hospital face-to-face activities.
\end{abstract}

Objective. The purpose of this paper is to describe the experiences of a medical school in the country as it navigated the sudden shift to full online learning vis-à-vis a framework on the barriers and solutions to online learning.

Method. This is a descriptive paper written from the perspective and observations of an administrator who participated in crafting the immediate response of the school to the sudden shift to online delivery and who worked with the stakeholders of the Ateneo School of Medicine and Public Health (ASMPH).

Results. To address concerns on time, skills and infrastructure, the school reprioritized its learning objectives for the remainder of the school year. It conducted in-service sessions for faculty while also immediately setting up a learning management system and a technical support team that was available on demand. Strategies employed included a deliberate switch to asynchronous learning, curation of content and creativity in delivery and assessment, and the reshaping of the management and public health activities into the online platform. To manage attitudes and provide institutional support, the school worked collaboratively with stakeholders and transformed its traditional support services of campus ministry, counselling, formation, and physical and mental health to be readily available online.

Conclusion. We described the experience of ASMPH when medical schools were forced to completely shift to online delivery of their programs because of the pandemic. We identified the barriers and solutions of online learning in medical education. The unique context of the ASMPH for having a dual degree in medicine and management; having an inter-disciplinal, non-departmentalized set-up at each year level; and, possessing the traditions of Jesuit education were instrumental in the school's ability to navigate this sudden shift.

Keywords: asynchronous learning, COVID-19, online learning, undergraduate medical education

\section{INTRODUCTION}

Corresponding author: Raymundo S. Baquiran, MD, MPH Ateneo de Manila University

School of Medicine and Public Health

Don Eugenio Lopez Sr. Medical Complex,

Ortigas Avenue, Pasig City, Philippines

Email: rbaquiran@ateneo.edu
On March 11, 2020 the World Health Organization declared the SARS-CoV-2 a global pandemic. ${ }^{1}$ In an effort to contain the spread of the infection, the entire National Capital Region (NCR) in the Philippines was placed on lockdown beginning on March 16, 2020. The enhanced community quarantine (ECQ) was imposed, forcing the entire educational system in the Philippines to suspend classes in all levels. ${ }^{2}$ The Association of Philippine Medical Colleges (APMC) that manages the National Internship Program issued a declaration on March 16, 2020 suspending the rotating medical internship and pulling out all interns in all participating training hospitals, not just in NCR but in the whole country. ${ }^{3}$ The Ateneo School of Medicine and Public Health (ASMPH), a medical school in Metropolitan 
Manila in the NCR, anticipated these pronouncements and as early as March 11, 2020, decided to pull out its clerks and interns from all of their rotations in hospitals and community settings. ${ }^{4}$

It became apparent that the global pandemic that was now affecting the Philippines will be for the long haul. Educational institutions, from the basic to the tertiary level, therefore, were forced to make a drastic shift from a physical classroom set up to a completely online setting, if only to finish the remaining three months of the school year 2019-2020.5 Medical schools across the country were not an exemption.

Medical education in the Philippines is generally conducted in the classroom or school setting for the first three years and in a hospital setting for the last two years. While elements of e-learning have been used as a vehicle in the roll out of the medical curriculum, at best, it is used as a supplementary tool of teaching and learning for some courses or modules and not as the primary tool nor setting for rolling out the program of learning. ${ }^{6}$ The sudden shift to full and complete online learning because of the pandemic, therefore, was a complete and unexpected disruption in the delivery of the curriculum for all medical schools.

For the ASMPH, although online learning is identified as a critical platform for the delivery of learning outcomes and as the main vehicle for its push for self-directed learning, the school was similarly stunned by this disruption, both for the lower year levels and most especially for those in the clinical years.

As the first medical school in the country to offer a dual degree and with an organizational structure that is inter-disciplinal (i.e., non-departmentalized), this paper describes the experience of the ASMPH in the sudden shift to full online learning for all year levels of its MDMBA Program. It looks at how the school navigated the immediate adjustment to complete online delivery of the three disciplines in the program (i.e., medicine, public health and management) by addressing the immediate concerns related to the sudden shift.

\section{METHODS}

This is a purely descriptive paper written from the perspective of an administrator who participated in crafting the immediate response on how the school suddenly shifted to online delivery and who helped supervise its overall implementation. The observations are based on meetings conducted with the chairs of the five academic year levels and the leadership of the school; the conversations with select students, staff and faculty; and, the teaching and learning guides uploaded by the faculty in the provisional learning management system that was immediately adapted because of the online shift.

The observations cover the period from March 2020 when the entire Metropolitan Manila was placed under
Enhanced Community Quarantine (ECQ) until the end of the academic year in June 2020.

The paper also uses the findings reported by O'Doherty et al. as framework for describing the ASMPH experience. ${ }^{7}$ In this exhaustive and integrative review, they identified the barriers to online learning in medical education. These are the following: (1) time constraint; (2) poor technical skills; (3) inadequate infrastructure; (4) absence of institutional strategies and support; (5) negative attitudes. Authors identified the following solutions: (1) improved educator skills; (2) incentives and reward for the time involved with development and delivery of online content; (3) improved institutional strategies and support; and, (4) positive attitude among all those involved in the development and delivery of online content.

\section{RESULTS}

\section{Description of the Student Population}

There were 860 students enrolled in the five-year levels at the time of shift to full online learning in March 2020. Majority were from an urban residence (84.3\%) and over $50 \%$ were categorized as rich (Table 1). Eight percent of the student population were on financial aid.

\section{Time Constraint, Technical Skills and Infrastructure}

There was uncertainty when classes were immediately suspended. With three more remaining months to complete the school year for both the classroom-based learning and the clinical rotations, it was not known if the suspension was temporary or long term. Following consultations with the school and university leadership, ASMPH quickly determined that the rest of the school year will be completed online, as opposed to the decision of the undergraduate units of the university to cut their term short. ${ }^{9}$

This decision was helpful because it allowed the school to immediately carry out remote teaching. Lectures were either recorded or live streamed through Facebook using closed FB groups of each year level. Because the university was already subscribed to the Google Educational Suite,

Table 1. Profile of ASMPH student population $(\mathrm{N}=860)$

\begin{tabular}{lc}
\multicolumn{1}{c}{ Variable } & $\begin{array}{c}\% \text { of } \\
\text { Respondents }\end{array}$ \\
\hline $\begin{array}{l}\text { Family Income (Monthly, self-reported data, in PHP)* } \\
\text { Low income (PHP 10,957-21,914) }\end{array}$ & 2.0 \\
Lower middle income (PHP 21,914-43,828) & 7.8 \\
Middle middle income (PHP 43,828-76,699) & 5.9 \\
Upper middle income (PHP 76,699-131,484) & 17.6 \\
Upper income (PHP 131,484-219,140) & 11.8 \\
Rich (PHP 219,140 and above) & 54.9 \\
\hline Place of Residence & \\
$\quad$ Urban & 84.3 \\
Rural & 15.8 \\
\hline
\end{tabular}

${ }^{*}$ Category for family income based on the Philippine Institute of Development Studies ${ }^{8}$ 
Google Classroom was immediately adopted as the Learning Management System. Zoom accounts were also immediately purchased to provide a platform for synchronous sessions. The remaining learning outcomes (LOs) were also streamlined so they can be accommodated within the time frame and within the limitations of remote teaching and online learning. The LOs that could not be delivered online (e.g., Laboratory and Clinical Skills Module) were parked and was to be delivered in the next schoolyear when faceto-face classes could resume.

To address the need for improved educator skills, within days of the suspension of classes, the faculty of ASMPH was convened to the first of a series of in-service sessions on remote teaching and online learning. The first in-service session, conducted face-to-face on campus but made available in real time through Zoom, focused on both the use of Zoom and the Google Educational Suite. The subsequent sessions conducted through Zoom focused on the sharing of faculty experiences with online teaching. For these sessions, the integration of the two faculties (medicine and management) worked to the school's advantage; the MBA faculty were able to share their prior experience in the use of their learning management system.

A Google Drive site was also set up to serve as a repository for freely sharing all instructional materials being used by the faculty during this time. This site allowed crosslevel learning on how to teach during this unique period. The site also became the clearinghouse for memoranda issued by regulatory bodies, the university and ASMPH on how to address the volatile situation.

To further assist the faculty, the lab tech team of the school was reorganized as a technical team available on demand for recording or livestreaming video lectures and for the management of the Google Classroom.

\section{Strategies on Online Learning}

\section{Switch to Asynchronous Learning}

The shift to complete online mode of delivery of learning outcomes was daunting for the faculty, especially for those who lacked the necessary technical skills and competences, the very first barrier identified in online learning. ${ }^{7,10}$

Likewise, early on in the shift to full online learning, the university in general and ASMPH in particular acknowledged that internet connectivity was a very critical consideration. The limited access to stable internet connection and internetcapable devices, more prominently for those living in the provinces, were the primary concerns of students. ${ }^{7}$ There was also the real challenge of sustaining learning while both faculty and students experienced the physical, mental and emotional stress of the pandemic, especially for families who were directly affected by the situation.

For these reasons, an immediate shift to asynchronous learning was adapted. Faculty members were instructed to make their video recordings, slide presentations and reading materials available in the Google Classroom or as a link accessible to students, which they were able to access at their own time and pace. This allowed for a more flexible set-up, relieving the burden and pressure of being online for extended periods of time.

This learning environment had the immediate effect of being student-centered. The online set-up made it possible for students to tailor fit their schedules and the pace by which they were able to learn and understand the material. Supplementary reading materials were made available for the students to direct them to the content which may not necessarily be must-knows, but would eventually be helpful for more advanced topics in a certain subject or module.

Although the mode of delivery was made primarily asynchronous, there were still synchronous sessions conducted, especially clinical preceptorial sessions and portions of small group discussions. Faculty also dedicated fixed virtual office hours for individual or group consultations with students.

\section{Curating Content and Creativity in Assessments}

Faculty members were given the liberty to reorganize their modules to fit the online environment as long as they remained faithful to the streamlined learning outcomes.

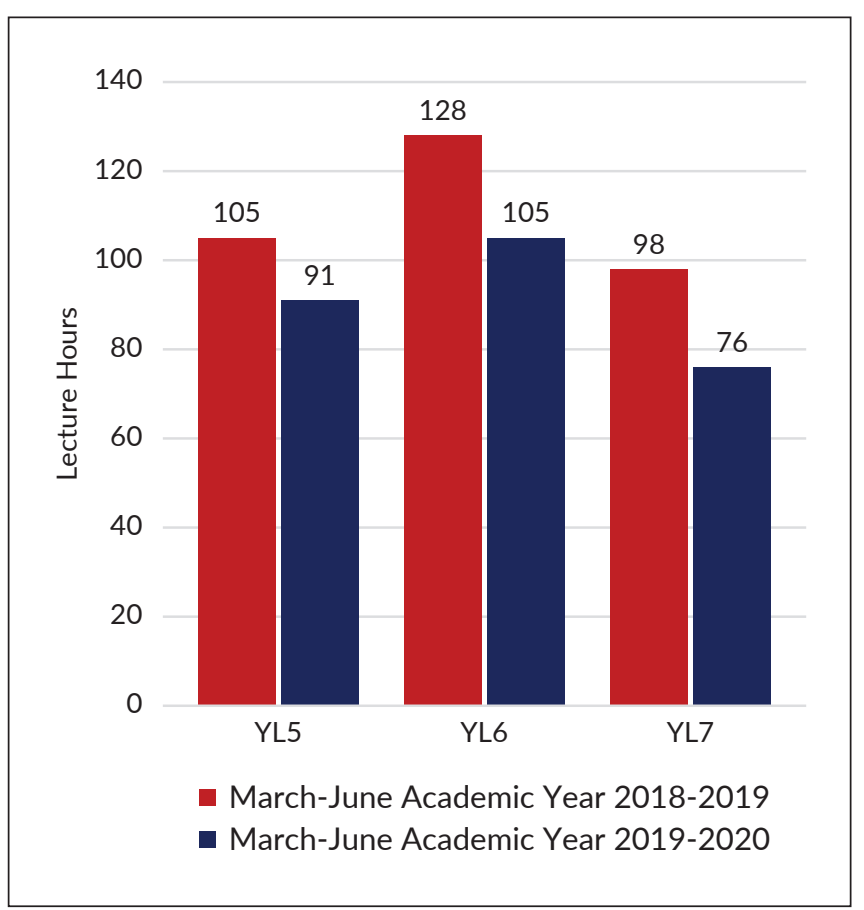

Figure 1. Comparison of lecture hours for the year level 5-7 modules from March-June of academic year 2018-2019 compared to the shortened lecture hours for their counterpart modules from MarchJune of academic year 2019-2020 affected by the suspension of classes.

YL, Year level 
This led to a significant reduction, an $18 \%$ drop on average comparing to the previous school year, in the number of lecture sessions in favor of self-directed and collaborative learning activities (Figure 1).

The online set-up also allowed faculty members to try out creative teaching strategies in delivering the learning outcomes for their specific modules. Faculty members came up with unique titles for their activities to capture the attention of their students. The "Lesion Online" lecture series in the Neurology Module, for example, covered the necessary and must-know topics that a $2^{\text {nd }}$ year medical student should be able to know and understand (Figure 2). Video lectures and accompanying PDF handouts were made available to students for a limited amount of time.

In the "YouNeu" Sessions, neurology cases were presented with students submitting answers to questions about the case on video format (Figure 3). This allowed the faculty to assess not just the knowledge, but also the demeanor and professionalism of the student as though they were interacting with a patient.

Discussion boards in Google Classroom served as a tool for curating content and allowed greater interaction between faculty and students.

The faculty also employed creative methods to do assessments, veering away from the traditional long examinations at the end of each module. Submission of student vlogs (i.e., video blogs) for return demo and for showcasing of skills was adopted. An online version of the OSCE was also developed through the use of multiple breakout rooms in Zoom.

Skills on physical examination (PE) were also assessed through video submission of a return demo carried out on a household member. For the $1^{\text {st }}$ and $2^{\text {nd }}$ year medical students, some of these recordings included performing targeted

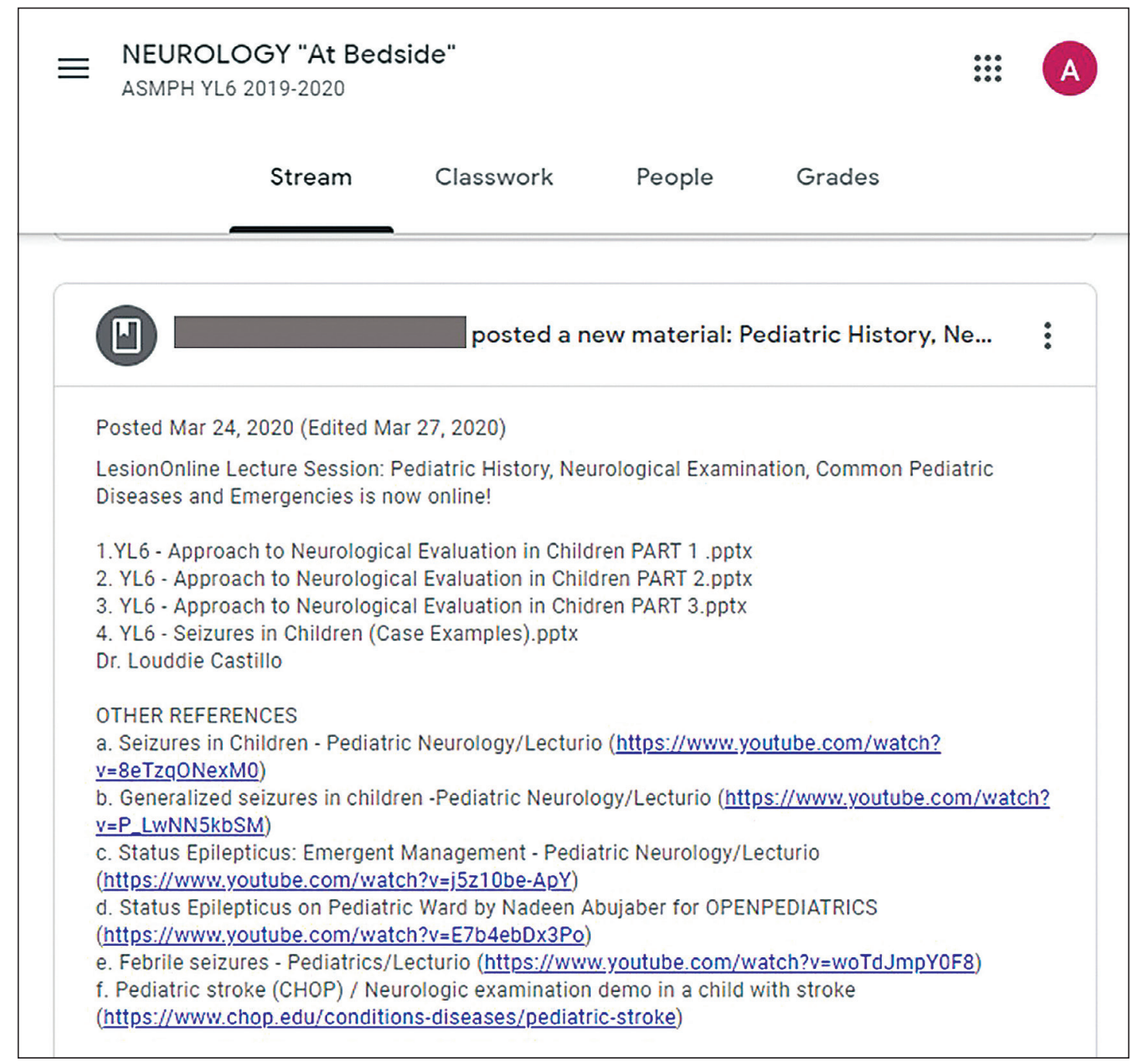

Figure 2. Sample Google Classroom interface for the YL6 Neurology module highlighting a post about the "LesionOnline" lecture series and the reference materials for the specific topic to be discussed.

YL, Year level 
physical examination such as fundamental neurologic examination or an organ-system specific PE.

The skill on splinting was also assessed through video submission. For suturing, particularly in the Obstetrics module, students practiced on animal (pig) tissue at home; this was assessed synchronously through Viber or Zoom.

Assessments were made against the learning objectives of the modules after they have been reviewed by the respective year level faculty clusters following the shift to full online learning. The faculty also felt that there were sufficient bases in giving quality point (QP) marks, rather than use a PassFail grading system. They, however, exercised "sensitivity, flexibility and compassion" in making the assessments; these virtues were emphasized by the university leadership at the very beginning of the pandemic. These considerations also extended to giving additional opportunities for students to achieve the learning objectives, sometimes in the form of tutorials, and were also applied to the remedial program that followed for students who still received conditional marks. ${ }^{11}$

\section{The "Virtual Rounds"}

Completion of the remaining three months for the two clinical years (clerkship and internship) through online learning presented an even more formidable challenge.

To allow clerks and interns to continue "seeing" patients, the clinical faculty in Internal Medicine set-up a "Virtual Rounds" where students received anonymized patient information on a regular basis through a closed and protected social media (Viber) group. The attending faculty-consultant fed the students daily clinical information about a patient in the hospital, which allowed the students to follow the patient's progress. The daily virtual rounds served as a platform for case discussion allowing the clerks and interns to continue learning about making differential diagnoses; committing

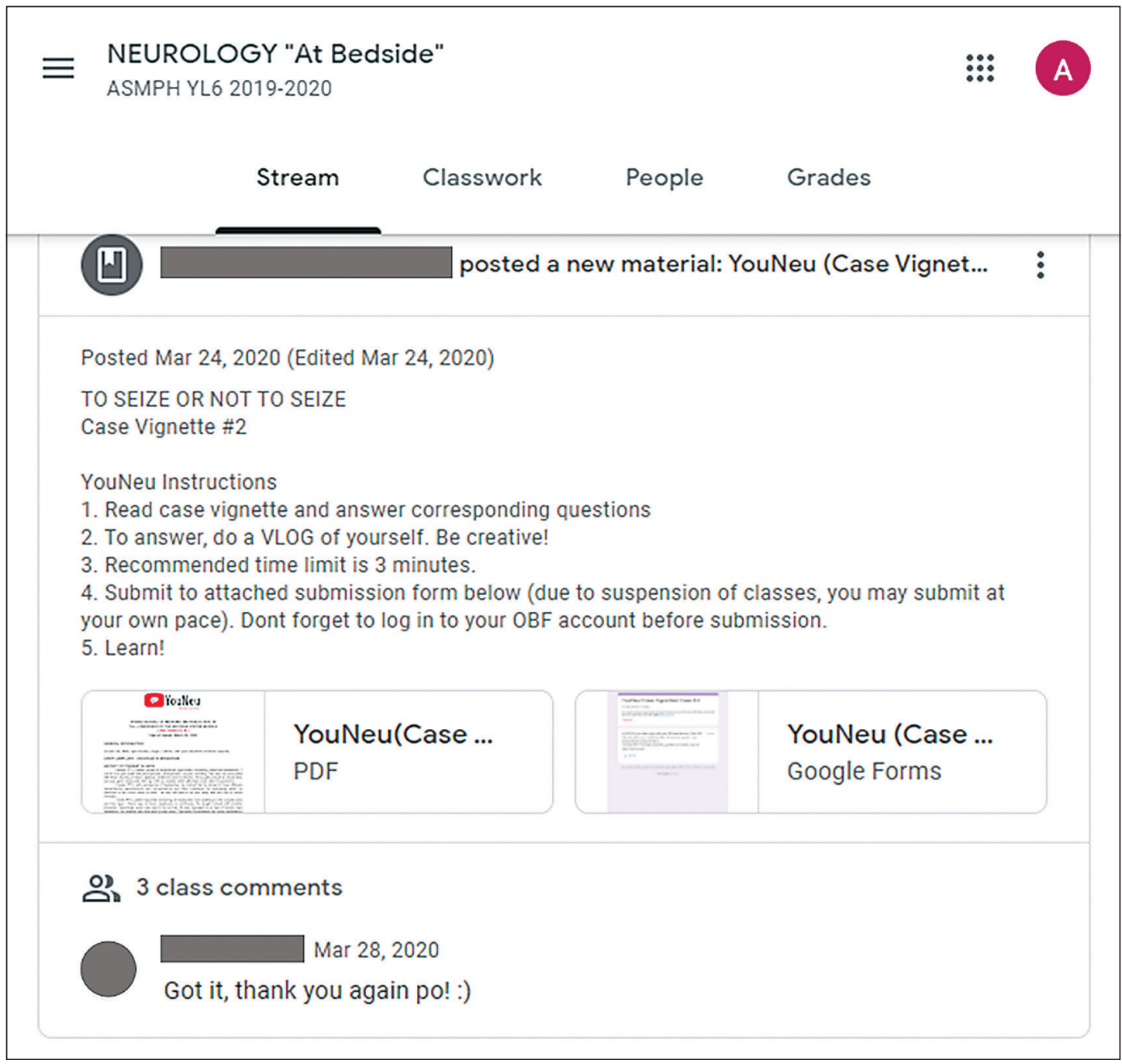

Figure 3. Sample Google Classroom interface for the YL6 Neurology module during the shift to online learning showing the "YouNeu" Sessions and the instructions for the activity.

YL, Year level 
to an assessment; and, learning about therapeutics and clinical management. All of these were conducted under the virtual but regular presence of consultants.

In the Ophthalmology rotation, the faculty shared with the students the anonymized history and physical findings of actual patients seen by the residents in the hospital. From the clinical information, clerks and interns were asked to come up with a diagnosis and treatment plan for the patient. They were then tasked to present and discuss with the faculty-consultant, either synchronously or asynchronously.

\section{Continuing Community Involvement}

Memoranda from both CHED and DOH directed schools to suspend community health activities because of the ongoing community transmission of the virus. ${ }^{12}$ This abruptly terminated the immersions and servicelearning activities of students with partner organizations and communities, a strong and distinct component of the ASMPH Program of Learning.

To maintain connection with communities, many of which were directly affected by the lockdown, the students continued to reach out to their respective partner organizations through all available remote means like the SMS, social media platforms and mobile calls. This allowed the students to find out how they could help with the difficulties and challenges imposed by the quarantine. Through the students' efforts, many of these communities were linked to organized relief operations staged through the Ateneo de Manila University's Disaster Response and Management Team and the Tanging Yaman Foundation. ${ }^{13}$ Additional guidance on how to help communities were also received from the webinars on public health organized by the Philippine Association of Family Physicians (PAFP) and the Philippine Academic Society on Community Medicine (PASCOM).

Outside of the curricular program, the ASMPH students extended their help to the medical front liners both in the hospital and community setting by distributing improvised personal protective equipment (PPE) that were extremely in short supply during the early part of the lockdown.

\section{Delivery of the MBA}

Compared to the organ system modules and the clinical rotations, the transition of the management courses to online delivery was much more polished. For one, the class size in management was much smaller. In addition, the MBA faculty has previous experience with the use of an established learning management system, whose use was expanded with this sudden shift.

Table 2 summarizes how the teaching-learning activities previously carried out face-to-face pre-pandemic were adapted to online delivery.

\section{Managing Attitudes and Institutional Support}

\section{Communicating with Stakeholders}

The personal fear about the COVID virus and the "volatile, uncertain, complex and ambiguous" setting that the pandemic heightened, had naturally increased the level of anxiety among faculty and students. ${ }^{14}$ To help manage this, the dean emphasized the necessity to communicate regularly with all stakeholders of ASMPH.

In the $3 \frac{1}{2}$ months when the ASMPH was suddenly thrust into full online learning until the school year was completed, 14 Town Hall meetings were held (Table 3), on top of the many memoranda that were issued to keep the whole community abreast. The Town Hall for students had attendance of more than $80 \%$ and were open to parents and guardians. With the faculty and staff, the Dean underscored the inevitable need, given the current situation, to complete the rest of school year through online learning and challenged the Faculty to rise up to the occasion with creative and out-of-the box alternatives. To the Students and their Parents/ Guardians, he reported on the volatility of the current situation and how the school is trying to adapt during these unprecedented times.

The Year Level Chair and Vice Chair in each of the five year levels also had their regular Town Hall meetings. These served as venue for hearing out students; getting their inputs; and working with them closely before schedules and learning activities were finalized. In many instances,

Table 2. Summary of teaching-learning activities that were previously delivered face-to-face and how the ASMPH adapted in delivering them online

\begin{tabular}{lll} 
Written Examinations & \multicolumn{1}{c}{ Activity } & Physical scantron examinations \\
\hline Laboratory Examinations & Move-type and practical examinations & Ooogle form examinations \\
\hline Small Group Discussions & Physical group discussion held on campus & $\begin{array}{l}\text { PowerPoint examination synchronously } \\
\text { administered to the batch }\end{array}$ \\
\hline Physical Examination Demonstration & Demo-return demo activity with patients & Held through Zoom \\
\hline Clerkship and Internship Rotations & Rotations in partner hospitals & $\begin{array}{l}\text { Virtual rounds where students are provided } \\
\text { with anonymized patient information }\end{array}$ \\
\hline Community Engagement & Service-Learning Activities on site with partners & $\begin{array}{l}\text { Mobile and online communication, } \\
\text { liaising, networking and referrals }\end{array}$ \\
\hline Management Courses & Classroom Delivery & Online Delivery \\
\hline
\end{tabular}


Table 3. Timeline of key events during the transition to online learning for the 2 nd semester of academic year $2019-20$

\begin{tabular}{|c|c|}
\hline Month & Key Events \\
\hline March 2020 & $\begin{array}{l}\text { - March } 11 \text { - Declaration of the COVID-19 pandemic by the World Health Organization } \\
\text { - March } 12 \text { - Town Hall and In-Service Faculty Dev on Google Suite and Zoom } \\
\text { - March } 15 \text { - YL8 and YL9 Faculty Town Hall meeting with the Dean to discuss the declaration of the COVID-19 } \\
\text { - Mandemic and the implications to face-to-face rotations } \\
\text { - Mear levels }\end{array}$ \\
\hline April 2020 & $\begin{array}{l}\text { - Medical, psychological, spiritual, and technological support services were launched during the Year Level Town Hall } \\
\text { meetings with their respective Chairs and Vice Chairs } \\
\text { - Continued transition to Google classroom for all the year levels and implementation of the various learning strategies } \\
\text { such as the "Virtual Rounds" activity for the clinical years } \\
\text { - April } 27 \text { - Town Hall and Faculty In-service on Online Assessments }\end{array}$ \\
\hline May 2020 & $\begin{array}{l}\text { - May } 3 \text { - Town hall meetings with YL8 and YL9 to discuss the plans for the remainder of the school year and the changes } \\
\text { to the roll out of the curriculum due to the suspension of face-to-face rotations } \\
\text { - May } 15-19 \text { - Town hall meetings with each of the five year levels regarding the forward movement by the school for } \\
\text { the } 2^{\text {nd }} \text { semester of academic year } 2019-2020\end{array}$ \\
\hline June 2020 & $\begin{array}{l}\text { - Conclusion of the } 2^{\text {nd }} \text { semester for academic year } 2019-2020 \\
\text { - Drafting of the policies for the Quality Point (QP) marks system in lieu of the pass or fail system which would be } \\
\text { implemented for the } 2^{\text {nd }} \text { semester }\end{array}$ \\
\hline
\end{tabular}

preferences of the students were honored in the setting of deadlines for submission. A dynamic mechanism for feedback was also created allowing both students and faculty to immediately address concerns and make quick adjustments to the online roll out.

\section{Support Services}

Alongside the academic program, the support services for students were also immediately set up online. Mentoring and coaching, pillars of the school's leadership and formation program, continued. Spiritual services through the Campus Ministry continued as well. An online mental health service and referral system was organized through the school's accredited psychologists and the Office of Health Services. This provided the necessary psycho-emotional and mental health support, a need that markedly increased during this time. Even the monthly Faculty Forum, also transformed online, was re-fashioned to serve as a support group for the faculty and staff.

To address concerns on connectivity, ASMPH set up a mechanism for lending out available laptops to students. Mobile broadband devices were also made available to those needing them. In immediate shift to full online learning, 21 students availed of these services.

\section{DISCUSSION}

For many educators, a major concern on the shift to online mode of delivery of lectures and assessments is the amount of time it takes to prepare the materials. ${ }^{7}$ In the Philippines, this barrier took an even greater magnitude because the shift was sudden and complete; and, it came at a time when online learning is not yet established as a platform for delivering the learning outcomes of Philippine medical schools.
O'Doherty identified that following as barriers to online learning in medical education: (1) time constraint; (2) poor technical skills; (3) inadequate infrastructure; (4) absence of institutional strategies and support; and, (5) negative attitudes of all involved. In this paper, we described our experiences with these identified barriers.

These barriers were also consistent with those identified in a national survey of medical students in the Philippines on online learning during the time of COVID-19. In this study, Baticulon et al. categorized these barriers as technological, individual, domestic, institutional, and community barriers. ${ }^{6}$ The ASMPH experience touches on these categories as well, highlighting primarily on the technological and operational challenges of transitioning to online learning and the necessary community support needed.

Institutional changes require a concerted effort from all the members of the community in order to be able to transition smoothly into a new way of doing things. The ASMPH was in the early stages of transitioning to a blended learning program when the COVID-19 pandemic began, allowing the school to adapt quickly to a completely online learning environment.

The unique context of the ASMPH, in our view, mitigated the expected difficulties in shifting to online learning. The inter-disciplinal (non-departmentalized) organization of each of the year levels, for one, facilitated fairly quickly the completion of the final schedule and calendar for the remaining three months. The streamlining and reprioritization of learning objectives were carried out from the bigger perspective of the year level terminal competences, rather than from the narrower objectives of modules and courses. The open discussion across disciplines in the year level also led to the crafting of creative learning and assessment strategies, enriched by the inputs of faculty from other disciplines. 
As an example, the "Virtual Rounds," whose goal was to bring the cases and experiences from the hospitals to the students vicariously, was originally conceived by a clinical faculty in medicine as a simple way of presenting cases for discussion. The final form whereby students were able to simulate a clinical setting with access to real-time patient information such as history and physical examination findings, laboratory and diagnostic results, and the current management for the patient was the result of the collective discussion and collaboration within the year level faculty. This also led to its adoption in various forms in the other departments.

The cross-level interaction of faculty through the inservice Zoom sessions and the shared Google site repository of model instructional designs and teaching materials also created a "learning in practice" atmosphere, described by Regmi and Jones as an enabler of online learning. This was further enhanced by the interaction between the two faculties of medicine and MBA, given the dual degree offering of the school. The emerging strategies, techniques and infrastructure were culled not only from the faculty's expertise in the disciplines of medicine, but also from the perspectives of management. This led to a systematic approach to an online learning experience that was shown to improve outcomes in students. The multidisciplinary and creative methods that address the learners' short-term and long term educational needs were noted to have the most impact. ${ }^{10}$

A final element that provided a substantial contribution to managing the potential negative attitude to online learning was the strong sense of community in the school. Underpinned by the Ignatian values of magis, cura personalis and being person-for-others, ASMPH consciously worked with the school's stakeholders in facing the challenges of the time. ${ }^{15}$

Communication was fundamental, which was why multiple town hall meetings were conducted with faculty, students and parents. This provided the avenue for addressing the academic needs and requirements of the students while taking into consideration the different variables such as technological infrastructure and limitations from both the students and the faculty which could possibly affect the learning process. Similarly, through town halls in their respective year levels, the students collaborated in finalizing dates and deadlines in the schedule, and even in the final choice of learning activities.

The refitting of traditional activities (spiritual activities, leadership and formation, coaching and mentoring) into the online platform proved to be a very useful in supporting the community. Through these online sessions, students were able to voice out their concerns and issues. The coaches, mentors and counsellors, in turn, were able to report these back to the administration as feedback.

The result of all of these, we believe, was an even more cohesive community that promoted a positive spirit in the midst of the fears and anxiety brought about by the pandemic, while full online delivery was carried out. Thus, in spite of the known barriers in implementing the online mode of delivery of learning outcomes, the ASMPH, through a collaborative culture between and among stakeholders, was able to complete the remainder of the year with the goal of maintaining its objective of providing the students the necessary skills needed to proceed to the succeeding year of their medical education.

\section{Limitations}

As previously noted, the experiences reported in this sudden shift from traditional classroom and hospital based medical education to a full online delivery were described from the perspective of an administrator who had an overview of the school-wide response to the situation imposed by the pandemic. While the views of the faculty and students were reflected as well by virtue of the observational methods employed, further studies using more rigorous methodologies are needed to evaluate the outcomes and impact of this sudden shift on the academic, physical and psycho-emotional well-being not only of students, but of the whole community as well, faculty and staff included. Likewise, continuing efforts are necessary to keep on improving the way learning objectives are delivered through online learning. The Ateneo University as a whole and the ASMPH in particular have commenced working on these two fronts through the Adaptive Design for Learning and the Ateneo Blue Cloud. ${ }^{16}$

\section{CONCLUSION}

We described the experience of ASMPH when medical schools were forced to completely shift to online delivery of their programs because of the pandemic. We identified the barriers and solutions of online learning in medical education.

To address concerns on time, skills and infrastructure, the school realigned and reprioritized its learning objectives for the remainder of the school year. It immediately conducted in-service sessions for faculty by creating a community of learners in the new mode of online delivery, while also immediately setting up a learning management system and a technical support team that was available on demand. Strategies employed included a deliberate switch to asynchronous learning; curation of content and creativity in delivery and assessment; and, the reshaping of the management and public health activities into the online platform. To manage attitudes and provide institutional support, the school worked collaboratively with stakeholders and transformed its traditional support services of campus ministry, counselling, formation and physical and mental health to be readily available online.

We contend that the unique context of the ASMPH for having a dual degree in medicine and management; having an inter-disciplinal, non-departmentalized set-up at each 
year level; and, possessing the traditions of Jesuit education were instrumental in the school's ability to navigate this sudden shift. It also helped that, pre-pandemic, the school already set the strategic goal of moving towards studentcentered learning that utilizes online learning as a principal modality. A critical element that was also extremely helpful in managing the transition was the open and dynamic communication among all stakeholders: faculty and staff, students and parents and guardians.

\section{Statement of Authorship}

Both authors participated in the data collection and analysis and approved the final version submitted.

\section{Author Disclosure}

Both authors declared no conflicts of interest.

\section{Funding Source}

This study has no funding support.

\section{REFERENCES}

1. Cucinotta D, Vanelli M. WHO declares COVID-19 a pandemic. Acta Biomed. 2020; 91(1):157-60. doi:10.23750/abm.v91i1.9397

2. Official Gazette, Community Quarantine Over the Entire Luzon and Further Guidelines of the Management of the Coronavirus Disease 2019 (COVID-19) Situation [Internet] 2020 [cited 2021 Jun] Available from: https://www.officialgazette.gov.ph/ downloads/2020/03mar/20200316-MEMORANDUM-FROMES-RRD.pdf

3. Association of Philippine Medical Colleges. National Internship Program Advisory: Complete Suspension of Internship Program in All Luzon Hospitals. [Internet] 2020 [cited 2021 Jun]. Available from: https://www.facebook.com/StudentNetworkAPMC/posts/onthe-complete-suspension-of-internship-in-all-luzon-hospitals-incompliance-wi/2940058662720463/

4. Alfonso C. Circular Memorandum No. D-01. Series 2020. Published online 2020.

5. Commission on Higher Education, Guidelines for the Prevention, Control and Mitigation of the Spread of Coronavirus Disease 2019 (COVID-19) in Higher EducationInstitutions (HEIs) [Internet] 2020. [cited 2021 Jun] Available from: https://ched.gov.ph/wp-content/uploads/CHED-COVID-2019Advisory-No.-3.pdf
6. Baticulon RE, Sy JJ, Alberto NRI, Baron MBC, Mabulay REC, Rizada LGT et al. Barriers to online learning in the time of COVID-19: a national survey of medical students in the Philippines. Med Sci Educ. 2021; 31(2):615-26. doi:10.1007/s40670-021-01231-z

7. O'Doherty D, Dromey M, Lougheed J, Hannigan A, Last J, McGrath D. Barriers and solutions to online learning in medical education - an integrative review. BMC Med Educ. 2018; 18(1):1-11. doi:10.1186/ s12909-018-1240-0

8. Philippine Institute for Development Studies, Poverty, the Middle Class, and Income Distribution amid COVID-19 [Internet]. 2020 [cited 2021 Jun]. Available from: https://think-asia.org/ bitstream/handle/11540/12319/pidsdps2022.pdf?sequence $=1$

9. Ateneo de Manila University. Remapping the Academic Life in the 2nd Semester SY 2019-2020 [Internet]. 2020 [cited 2021 Jun]. Available from: https://www.ateneo.edu/remapping-academic-lifesecond-semester-sy-2019-2020.

10. Regmi K, Jones L. A systematic review of the factors - Enablers and barriers - Affecting e-learning in health sciences education. BMC Med Educ. 2020; 20(1). doi:10.1186/s12909-020-02007-6

11. Ateneo de Manila University, Enhanced Community Quarantine [Internet]. 2020 [cited 2021 Jun]. Available from: http://www. ateneo.edu/sites/default/files/20200317.2300 Memo Covid.pdf

12. Commission on Higher Education, Guidelines on the Gradual Reopening of Campuses of Higher Education Institutions for Limited Face-to-Face Classes During the COVID-19 Pandemic [Internet]. 2021 [cited 2021 Jun] Available from: https://ched.gov.ph/wp-content/uploads/CHED-DOH-JointMemorandum-Circular-No.-2021-001-Guidelines-on-the-GradualReopening-of-Campuses-of-Higher-Education-Institutions-forLimited-Face-to-Face-Classes-during-the-COVID-19-Pandemic. pdf

13. UCA News, Philippine Jesuit charity groups unite against Covid-19 [Internet]. 2020 [cited 2021 Jun]. Available from: https://www. ucanews.com/news/philippine-jesuit-charity-groups-unite-againstcovid-19/88258\#

14. Norazmi MN, Hohmann AW, Bradley J. Understanding leadership styles checklist 256. Malays J Pathol. 1990; 12(2):89-95.

15. Ateneo De Manila University, About ASMPH: The School and Its Guiding Principles [Internet]. 2021 [cited 2021 Jun]. Available from: https://www.asmph.ateneo.edu/about

16. Alfonso C. From Blue Ocean to Blue Cloud: Ateneo School of Medicine and Public Health Online Learning; 2020. doi:10.1109/ MCAS.2014.2360784 